\title{
Systematic literature review: effects of digital technology on business models and sustainability
}

\author{
Vidmar Doroteja ${ }^{1}$ and Pucihar Andreja ${ }^{1}$ \\ 1 University of Maribor, Faculty of organizational sciences, Kidriceva cesta 55a, 4000 Kranj, \\ Slovenia \\ doroteja.vidmar@um.si
}

\begin{abstract}
In recent years we are observing two simultaneously ongoing transformations in enterprises. Through systematic literature review we explored existing literature that combines digital technology, business models and sustainability. Using protocol that we placed beforehand we assessed collected papers, classified them and analyzed them focusing on the methodology used, common themes, open research questions and theoretical background.
\end{abstract}

Keywords: digital technology, business model, sustainability.

\section{Introduction}

In recent years we are observing two simultaneously transformations in the enterprises. Transformation towards sustainable and transformation towards digital - two continuous, ongoing processes that are developing under internal and external pressures and result in changes of the elements of business model (BM). BM can be used as an analytical unit to help us explore the logic and economics of production and consumption in fulfillment of specific needs through specific artifacts [1]. We will be examining the processes of transformation towards sustainable and towards digital in the observed enterprises through the lens of BM.

Globally, humans are not making enough progress in addressing sustainability issues [2], and with time, these challenges are only getting more severe, while our time and options for action are only getting slimmer [3]. Viewing sustainability as the ability to fulfil the present needs without restricting the ability to fulfil those needs in the future [4], combined with the triple bottom-line perspective, according to which sustainable value is a balance between economic, environmental and social value [5] - implies that responsibility and profit should be shared equally between everyone involved in production, consumption and the aftermath of the product/service.

In today's economy the financial capital is overvalued, human capital undervalued and natural capital is not valued at all [6]. Our society lets enterprises privatize profits and socialize costs of their irresponsible use of resources [6], [7]. This economical model needs to be replaced with more sustainable alternative. Wealth inequality needs to be reduced and prices, taxes and incentive systems adapted in such way, that they take into account the real costs that consumption imposes on our environment [2]. 
In the time when impact of information technologies (IT) on business is already enormous and still growing, reaching digital maturity through digitalization is imperative for enterprises to ensure their competitiveness on the market [8], [9]. Resourceefficiency can be achieved through the use of IT [10], but information systems (IS) sustainability research needs to go beyond Green IT and energy-informatics, that deal primarily with increasing energy-efficiency of technologies [11]. The effects of IT on sustainability are still underestimated and understudied [12]. However, with the growing use of IT, it's influence on innovation for sustainability and thus sustainability is rising as well [13]. This is the time for IS scholars to view sustainability as the imperative in their research agenda and act with the urgency [14].

Our interest in reaching sustainability in enterprises stems from the limited ability of the consumers to reach sustainability in their lives. Sustainability of an enterprise can be reached only if the whole supply chain, or at least parts below it, act sustainably [11]. This implies that a consumer, the link in the traditional supply chain that most chains lead to, can be only as sustainable as the enterprises from which they are consuming products/services. This un-sustainable predisposition of our whole economy is in dire need of change. We argue that IS' strategic roles (automation, information and transformation) can lead our society towards sustainability [11], [13].

The need for inter-disciplinary research on sustainability and IS was previously observed by other researchers [11], [14], [15] and it is becoming more visible in business, where emerging sustainability-oriented BMs (e.g. PSS (product-service systems), CE (circular economy)) are driven by widespread use of IT [13], [16] and enterprise information systems (EIS).

We chose BM perspective to evaluate change that IT is causing in sustainability of enterprises. In this paper we aim to asses existing inter-disciplinary research on the effects of IT on sustainability performance, through use of business model innovation (BMI). We aim to identify current research gaps, search for possible contributing variables and explore interconnections between them. Findings from this paper will be used as a base for further research.

The paper is organized as follows: in the section 2 findings from existing literature are presented, in section 3 , we present methodology, including selection protocol and quality assessment criteria. In the section 4 we present the results of systematic literature review and in section 5, we discuss the findings and present limitations, possible further research directions and conclusions.

\section{Previous literature reviews}

While searching for literature, we found a handful of literature reviews exploring the connections between IT, sustainability and BM. Literature reviews were published between the years of 2007 and 2018, they tackled the topics from various angles, emphasizing very different areas and were of various rigor and relevance. In table 1 we present in chronological order those that were of relevance to us. 
Table 1. Previous literature reviews.

\begin{tabular}{|c|c|c|}
\hline Reference & Journal & Content \\
\hline$[17]$ & MIS Quarterly & $\begin{array}{l}\text { Demonstrating and advocating a research agenda to estab- } \\
\text { lish subfield of IS tackling the issue of high energy use; } \\
\text { focus on research opportunities for IS scholars; proposed } \\
\text { framework for »energy informatics«. }\end{array}$ \\
\hline [12] & MIS Quarterly & $\begin{array}{l}\text { Focus on environmental sustainability; developing re- } \\
\text { search agenda for IS innovation for sustainability; author } \\
\text { demonstrated IS can play a key role in shaping attitude, } \\
\text { enabling and transforming economic and environmental } \\
\text { sustainability in organizations; belief-action-outcome } \\
\text { (BAO) framework. }\end{array}$ \\
\hline [18] & $\begin{array}{l}\text { ERSCP-EMSU } \\
\text { Conference }\end{array}$ & $\begin{array}{l}\text { Technology is discussed as a driver of BMI; focus on } \\
\text { BMI as strategic factor that supports the adoption of more } \\
\text { sustainable products, processes, supply chains; moving } \\
\text { closer to conceptualization of sustainable BMs. }\end{array}$ \\
\hline [11] & $\begin{array}{l}\text { Journal of Strategic } \\
\text { Information Sys- } \\
\text { tems }\end{array}$ & $\begin{array}{l}\text { Authors developed sustainability framework based on re- } \\
\text { source-based-view (RBV); examined strategic roles of IS } \\
\text { (automate, informate, transform and infrastructure); call } \\
\text { for IT to move beyond reducing energy consumption. }\end{array}$ \\
\hline [1] & $\begin{array}{l}\text { Journal of Cleaner } \\
\text { Production }\end{array}$ & $\begin{array}{l}\text { Advancing research on sustainability by adopting BM } \\
\text { perspective; authors examined literature on BMs, pro- } \\
\text { posed requirements a BM should meet in order to support } \\
\text { innovations for fostering sustainability and proposed a set } \\
\text { of questions that should guide future research agenda. }\end{array}$ \\
\hline [19] & Business Horizons & $\begin{array}{l}\text { Exploring whether »sharing economy« is only a trend or a } \\
\text { real shift in consumption of goods; authors discuss the } \\
\text { role of technology, shift in values of consumers, potential } \\
\text { of sharing BMs. }\end{array}$ \\
\hline [20] & Sustainability & $\begin{array}{l}\text { Investigating the opportunities and challenges digitaliza- } \\
\text { tion brought to public transport and possible contributions } \\
\text { towards sustainability; authors discuss economic, envi- } \\
\text { ronmental and social perspectives through studied litera- } \\
\text { ture. }\end{array}$ \\
\hline [21] & $\begin{array}{l}\text { PICMET Confer- } \\
\text { ence }\end{array}$ & $\begin{array}{l}\text { Exploring the impact of Internet of Things (IoT) has on } \\
\text { innovation for sustainability; authors aimed to examine } \\
\text { enablers and barriers in innovation for sustainability; dis- } \\
\text { cuss the potential of internet of things (IoT). }\end{array}$ \\
\hline [22] & $\begin{array}{l}\text { Technological } \\
\text { Forecasting \& So- } \\
\text { cial Change }\end{array}$ & $\begin{array}{l}\text { Through study of literature authors identified a research } \\
\text { gap on integration between circular economy }(\mathrm{CE}) \text { and } \\
\text { large data; proposed a framework; set foundations for fu- } \\
\text { ture research. }\end{array}$ \\
\hline
\end{tabular}


Through literature reviews we can observe how research on reaching sustainability through the use of IT in organizations developed - first steps in 2010 were solely about IS scholars helping decrease energy use in and lessen environmental degradation. Technology is already seen as one of the drivers for sustainable advancement and sustainable BMs are already mentioned.

In 2011 we notice the need to broaden the contribution of IS to sustainability, which meant including economic, environmental and social sustainability. In 2013 scholars argued for advancements in research through BM perspective. After 2016 we observe shift in consumer values, causing rise of novel BMs and foci of research being how specific types of BMs, fields and technologies tackle sustainability.

\subsection{Key findings from literature}

What we can learn from the literature is that sustainability advancements of society are not likely without improving sustainability in organizations [23]. Significant sustainability impact can be reached through the use of technologies or through BMI [21], meaning that not only what organizations do for business, but complete shift in the way the business is conducted is required [24]. BMs are seen as key initiators [23] or at least support for systematic and continuous changes in corporate sustainability [18], [24].

Relating to technology, BMs are seen as mediators between how technology is made, technology itself and how it is eventually used [1]. Its »role as a market device« can manifest in different ways: creation of new business models through which technologies are used, adoption of new technologies in existing BMs, existing BM triggering technological innovation or technologies triggering creation of new BMs [1].

Not much of the research focused on the role of technology to address issues of sustainability [11], [21], but in existing research, technologies are seen as key, often undervalued and underused, factors enabling the implementation of sustainable BMs [12], [21].»Increased digitalization is seen to provide multiple value creation mechanisms and possibilities by enhancing the more effective use of resources « [21]. It is well established that IT resources enable various business capabilities, from what we can argue that IT resources may be critical to develop capabilities to tackle sustainability issues [11]- and these connections should be explored in order to develop body of knowledge and improve sustainability [12].

Even though the environmental perspective of sustainability tends to be most commonly addressed, social implications of business need to be considered as well. Through transformation of supply chain businesses can stimulate social changes (e.g. decreased poverty, improved health, gender equity, life quality) [21].

All three dimensions of sustainability need to be balanced, which poses a major challenge [21]. It has been shown that environmental and economic performance reinforce each other [11] and enterprises focus firstly and mostly on economic sustainability and then on environmental sustainability - while social implications tend to stay unaddressed [11].To tackle this issue of not-addressing social sustainability, every enterprise should tackle sustainability from two organizational departments: human re- 
sources and operations [11]. While both departments should be concerned with economic sustainability, operations should additionally consider environmental sustainability and human resources social sustainability.

Our global economic system is set for enterprises, who are not held responsible for full cost of their unsustainable activities - if they were, they would have the incentive to act sustainable [17]. Market regulation, along with BMI and technological progress are seen as three essential drivers of innovation for sustainability [18] - implying that markets need to be regulated for sustainability.

Research agenda for IS and sustainability should focus on »informing beliefs, enabling actions, and transforming outcomes « [12]. And while humanity faces rising threats that are caused by unsustainable actions of individuals and enterprises, enterprises are experiencing threats of changed business environment. Changes are now caused in large part by rising digital maturity of competitors [8] whose use of IT is enabling innovative BMs. Fast growth of these potentially more sustainable BMs [25] is fueled by shift in values of individuals, who turn more and more toward »liquid and adaptable lifestyle «. Possession is no longer seen so much as commodity but as constraint to mobility - causing the dramatic drop in the value of ownership [19].

It should also be noted that changes in consumption of individuals might influence sustainability positively or negatively [25]. In order to tackle this issue, access to accurate and timely information is necessary [20]. In transport system one of the key examples when talking about sustainable BMs, IT is used to continuously monitor the data and use it to support decisions of system operators and users [26]. Collection and analysis of information is the activity that IS/EIS can bring to other fields and help drastically improve sustainability efforts simply by informing [12], [17], [22].

\section{Methodology for systematic review of literature}

Based on various guidelines for conducting systematic literature reviews [27]-[29], we outlined the protocol for conducting systematic literature review. The protocol must be in place beforehand in order to protect us from literature bias [28]. Unfortunately, this does not protect against publication bias, which needs to be accounted for [28].

\subsection{Review protocol}

Based on the recommendations [28], [29] we decided to include the following steps:

Research question. Goal of this literature review is to assess scope, nature and quality of academic literature on inter-disciplinary research combining the fields of sustainability, effects of IT and BMI. Our focus is on the role of IT in BMI towards sustainability. We aim to identify gaps in research, explore interconnections between contributing factors and prepare a base to be used for further inter-disciplinary research.

Search strategy. everything needs to be documented! (To ensure that the search for obtained literature is at least partially repeatable.) 
Search was conducted exclusively through electronic sources. We searched in the top IS digital libraries (Web of Science, Scopus, Science Direct, IEEExplore) and AIS Senior Scholars' Basket of Journals (European Journal of Information Systems, Information Systems Journal, Information Systems Research, Journal of AIS, Journal of Information Technology, Journal of MIS, Journal of Strategic Information Systems, MIS Quarterly)

All papers from digital libraries were retrieved through queries covering all three areas of interest: IT (digital transformation, digital maturity, digitalization, digitization), sustainability (sustainability, sustainable innovation, innovation for sustainability), BMI. We developed keywords and constructed search strings including all three areas of interest. Search strings were adapted based on the demands of search mechanisms of different databases to ensure optimal collection of results. Papers retrieved directly from journals were obtained by custom search strings combined with manual search. Search strings were adapted based on the search mechanisms of each webpage.

Additionally, we performed backward literature search procedure, based on papers that were obtained through search in digital libraries that passed the practical screen and quality assessment. Lists of references were searched for additional papers.

Practical screen. field of IS unique for combining qualitative and quantitative research, guiding towards adapted systematic literature review (SLR) procedure [29]. Once the search results are obtained, they need to go through screening process to establish their relevance [28]. In this step we provide a set of inclusion/exclusion criteria we used to determine whether the obtained papers should be included in the literature review.

All papers included in literature review needed to be: accessible (we need to be able to gain full access), written in English, include topics of information technology, sustainability and business models (based on title, keywords and abstract).

Quality assessment. Papers obtained through described search strategies and not excluded through practical screening process were subjected to additional quality assessment. Criteria that we selected for quality assessment of papers are: were all three topics of interest addressed? Was paper published in scientific journal or conference proceedings? Papers that didn't meet the selected criteria were excluded, since objective of quality assessment is to exclude papers that passed practical screen, but their focus is not in the areas that are of interest to us, or the quality of paper is questionable.

For us, quality assessment was especially important, since term sustainability is often used in two different meanings. We are focused on sustainability related to the Brundtland commission definition [4] and focusing on at least one of the scopes of the triple bottom line - environmental, social and economic profit [5] Often, sustainability is mentioned only as long term survival of organization - this is not sustainability that we are focused on, and papers focusing on this aspect of sustainability were excluded.

Quality classes. All papers will be classified [27] into two categories: Class A papers - papers published in impact factor journal and Class B papers - professional reports, papers published in less-reputable journals and in conference proceedings.

Data extraction and analysis. aim of this review is to assess scope, quality and maturity of papers written on topics of digital transformation, need for sustainability and their impact on BM. 
Papers were classified into 2 quality classes described above, and for each paper we checked the following: where was the paper published; year of publication; methodology; is problem clearly defined; is problem statement answered; are crucial terms clearly defined; what methods and approach were used; are there any theories mentioned; what were the main factors mentioned; did authors identify any research gaps?

\section{$4 \quad$ Results}

After completing the search for papers through electronic databases and AIS Senior Scholars' Basket of Journals, practical screen and quality assessment of obtained papers was conducted. Backward search for additional papers through the references of all included papers was conducted. Additionally, practical screen and quality assessment of papers identified through backward search was conducted. In the end, we were left with 24 papers that were relevant to us.

Papers that we decided to include in our review were published from 2007 to 2018.

All included papers were divided into 2 quality classes, A and B, adapted from [27], we have 13 class A papers (published in high impact factor journal) and 11 class B papers (professional reports, papers published in less-reputable journals and conferences - as can be seen from table 2 .

Table 2. Papers included in systematic literature review.

\begin{tabular}{|c|c|c|c|}
\hline \# & Title and reference & Year & Class \\
\hline 1 & $\begin{array}{l}\text { A new electronic service for UK theses: access transformed by EThOS } \\
\text { [30] }\end{array}$ & 2007 & A \\
\hline 2 & $\begin{array}{l}\text { The fourth wave of digitalization and public transport: opportunities and } \\
\text { challenges [20] }\end{array}$ & 2016 & A \\
\hline 3 & $\begin{array}{l}\text { How GoGet CarShare's product-service system is facilitating collabora- } \\
\text { tive consumption [16] }\end{array}$ & 2017 & A \\
\hline 4 & $\begin{array}{l}\text { Driving business transformation toward sustainability: exploring the im- } \\
\text { pact of supporting IS on the performance contribution of eco-innova- } \\
\text { tions [13] }\end{array}$ & 2017 & A \\
\hline 5 & $\begin{array}{l}\text { What makes a sustainable business model successful? An empirical } \\
\text { comparison of two peer-to-peer goods-sharing platforms [31] }\end{array}$ & 2018 & A \\
\hline 6 & $\begin{array}{l}\text { Unlocking the circular economy through new business models based on } \\
\text { large-scale data: an integrative framework and research agenda [22] }\end{array}$ & 2017 & A \\
\hline 7 & $\begin{array}{l}\text { Getting smart about urban mobility - aligning the paradigms of smart } \\
\text { and sustainable [26] }\end{array}$ & 2016 & A \\
\hline 8 & $\begin{array}{l}\text { Information systems and environmentally sustainable development: en- } \\
\text { ergy informatics and new directions for the IS community [17] }\end{array}$ & 2010 & A \\
\hline 9 & Information systems innovation for environmental sustainability [12] & 2010 & A \\
\hline 10 & $\begin{array}{l}\text { From green to sustainability: information technology and an integrated } \\
\text { sustainability framework [11] }\end{array}$ & 2011 & A \\
\hline 11 & $\begin{array}{l}\text { Business models for sustainable innovation: state-of-the-art and steps to- } \\
\text { wards a research agenda [1] }\end{array}$ & 2013 & A \\
\hline 12 & Sharing yet caring $[25]$ & 2018 & A \\
\hline 13 & $\begin{array}{l}\text { Innovative business models for smart cities: overview of recent trends } \\
\text { [32] }\end{array}$ & 2012 & B \\
\hline
\end{tabular}


14 Crowdsensing-based transportation services - an analysis from business 2016 B model and sustainability viewpoints [33]

15 Developing disruptive innovations for sustainability: a review on impact 2017 B of internet of things (IOT) [21]

16 Exploration of simulation-driven support tools for sustainable product 2017 B development [34]

17 Metals industry: road to digitalization [35] $2017 \quad$ B

18 Second-movers' advantage of utilizing big data to enhance sustainability 2016 B performance: the case of elevator industry [36]

19 An industry 4.0 research agenda for sustainable business models [37] $\quad 2017 \quad$ B

20 Re-distributed manufacturing to achieve a circular economy: a case 2017 B study utilizing IDEF0 modeling [38]

21 Towards a conceptual framework of business models for sustainability 2010 B [18]

22 Organizational self-renewal: the role of green is in developing eco-ef- 2012 B fectiveness [39]

23 Developing smart services by internet of things in manufacturing busi- 2018 B ness [40]

24 A new electronic service for UK theses: access transformed by EThOS 2007 A [30]

\section{Qualitative assessment:}

Methodological approaches that were most commonly used were literature review and case-study. Rigor of literature reviews in class A and class B varied.

The most prominent difference between classes A and B was in case-study approach, where authors of class A papers used mixed approach, combining case-studies with other methods or at least provided reader with multiple case-studies, in-depth explanation and cross-case analysis.

In one instance case-study was conducted in the same enterprise multiple times over the course of 2 years and combined with 15 in-depth interviews [16].

One article cross-analyzed case-studies from 8 different enterprises and described methodology and results in great depth [13].

Theories were not commonly mentioned in selected papers. Those that were mentioned, are: Theory of two-sided (and multi-sided) markets [31], [33], resource-based view (RBV) [11], [13], product life-cycle [34], [37], sociotechnical theory [26], technology acceptance model (TAM) [12], and agency theory [25].

Worth mentioning is that theory of two-sided markets is often used with platform economy, while resource-based view is sometimes mentioned if the study focuses on ecological sustainability and limited resources.

Recurring themes are platform economy (also collaborative economy, sharing economy, collective economy), public/communal transport, (PSS), (CE).

Sustainability is in most cases understood as triple bottom line perspective [5] environmental, social and economic gains -6 instances, or as ecological/environmental perspective - in 5 cases. Interestingly, even though not very popular, economic and 
environmental perspective are sometimes considered combined and economic perspective is sometimes considered as sole sustainability perspective. Social perspective on sustainability is mentioned only as a part of triple bottom line trio.

Regarding definitions of $\mathbf{B M}$, there were three general options: either no definition of BM is offered, a type of BM is mentioned, or other authors' definitions are given as an example. The only exception to this was viewing BM as an analytical perspective that helps us understand economic logic of need-fulfilment through artefacts [1], [18].

We already spoke about duality of term sustainability. Additionally, we soon noticed that not many papers mention term digital transformation. Instead the use of IT and the effects of IT on business practices is often mentioned, as well as digitalization or even digitization and their effects. Often state of the art technologies are mentioned - IOT, big data, smart ...

We see no need to use the term digital transformation, or even digital maturity, as the term in itself only describes the effects that IT has on business environment. We therefore included all results that dealt with interconnections between sustainability, BMs and IS or IT.

In the next step, we identified moderating and mediating variables from the research. We only found one possible mediating variable (MeV) - BMI. BMI connects IT and demand for sustainability, creating hybrid solutions, which can be deployed on a larger scale than without the use of IT [13], potentially reaching higher impact on overall sustainability performance.

We identified several moderating variables $(\mathrm{MoV})$, which we sorted into two groups:

MoVs affecting relationsip between Green IT and BMI: proactiveness of IT stance [13]; use of supporting IS [13]; organizational aspiration level of eco-innovation use [13].

MoVs affecting relationsip between BMI and Sustainability: putting pro-social objectives first, in order to attract users [16]; adequate/critical mass of users [16], [31], [33]; crowdsourcing [33]; hybrid business/social models [13], [16]; offering complementary activities instead of radical adoption of new technologies to reach sustainability objectives [16]; design and execution of BMs [31]; strategic agility [31]; constant BMI [31].

\section{Discussion of key findings}

Focus of this research is to determine whether IT can act as an enabler and driver of increased sustainability through BMI. The reasoning behind the idea is that enterprises are rarely leading the sustainability movement - and through the presence of mostly unsustainable products and services on the market they affect customer choice. Therefore, they are not only responsible for their own non-sustainability, but are co-responsible for non-sustainability of customers, that they affected through lack of sustainable options and adequate disposal methods.

Inter-disciplinary research on the topic of sustainability, BMs and IT is still in its birthing stage, which is evident from low number of relevant results, lack of diversity 
and choice in methodology, gap in methodology pointing toward the need to conduct more qualitative research and eventually quantitative research.

However, literature obtained from high impact journals shows that the interest of academia for inter-disciplinary take on proposed subjects deserves attention. Researchers from IS community often act ignorant about the fact, that they too can tackle the problems of sustainability [17]. Some researchers focus on research opportunities, so that other information systems scholars can focus on delivering solutions [17]. Research on contribution of IT and EIS for sustainability is limited and rarely stretches beyond reducing the consumption of energy [11] and additional insight on how to use IS to transition to sustainability is needed [15]. In first attempts, information systems scholars focused on energy and resource reduction (Green IT or Green in IT), or the practices where IT is a contributor towards sustainability [13]. Almost a decade later, IT is seen as a possible solution that will enable us to reach sustainability (therefore we will become Green by IT). Some authors [23] propose research on how BMs for sustainability evolve in the process leading to industry transformations. They believe that insight is needed on how impacts of such BMs can be managed or measured.

"The economics of sustainability need not be permanently set for organizations. As regulations change, the economics change and markets can become mechanisms for sustainability" [17]. We are observing these changes in economy through occurrence of new and changed BMs. A pattern emerges from the literature, proposing IT is often seen as a driver and enabler of BMI, which is used to reach sustainability of enterprises.

Acknowledgements. This research was supported by the Slovenian Research Agency; Program No. P5-0018-Decision Support Systems in Digital Business.

\section{$7 \quad$ References}

[1] F. Boons and F. Lüdeke-Freund, 'Business models for sustainable innovation: state-ofthe-art and steps towards a research agenda', J. Clean. Prod., vol. 45, pp. 9-19, Apr. 2013.

[2] W. J. Ripple et al., 'World Scientists' Warning to Humanity: A Second Notice', Bioscience, vol. 67, no. 12, pp. 1026-1028, 2017.

[3] G. I. Broman and K.-H. Robert, 'A framework for strategic sustainable development', J. Clean. Prod., pp. 1-15, 2015.

[4] World Commission on Environment and Development, 'Report of the World Commission on Environment and Development: Our Common Future', 1987.

[5] J. Elkington, Cannibals with Forks: The Triple Bottom Line of 21st Century Business. John Wiley \& Son Ltd, 1997.

[6] J. Potočnik, 'Keynote speech: Transition to a Sustainable Economy - The Critical Role of Digital Transformation', in 31ST Bled eConference Digital Transformation: Meeting the Challenges, 2018.

[7] University of California and Vox, Climate Lab S1 E2: Going green shouldn't be this hard. 2017.

[8] G. C. Kane, D. Palmer, A. N. Phillips, D. Kiron, and N. Buckley, 'Achieving Digital 
Maturity', 2017.

[9] G. C. Kane, D. Palmer, A. N. Phillips, D. Kiron, and N. Buckley, 'Coming of Age Digitally: Learning, Leadership, and Legacy', 2018.

[10] R. Gholami, A. B. Sulaiman, T. Ramayah, and A. Molla, 'Senior managers' perception on green information systems (IS) adoption and environmental performance: Results from a field survey', Inf. Manag., vol. 50, pp. 431-438, 2013.

[11] V. Dao, I. Langella, and J. Carbo, 'From green to sustainability: Information Technology and an integrated sustainability framework', J. Strateg. Inf. Syst., vol. 20, pp. 63-79, 2011.

[12] N. P. Melville, 'Information Systems Innovation for Environmental Sustainability', MIS $Q .$, vol. 34, no. 1, pp. 1-21, 2010.

[13] A. Hanelt, S. Busse, and L. M. Kolbe, 'Driving business transformation toward sustainability: exploring the impact of supporting IS on the performance contribution of eco-innovations', Inf. Syst. J., vol. 27, no. 4, pp. 463-502, 2017.

[14] S. Seidel et al., 'The Sustainability Imperative in Information Systems Research', Commun. Assoc. Inf. Syst., vol. 40, 2017.

[15] A. Malhotra, N. P. Melville, S. M. Ross, and R. T. Watson, 'SPURRING IMPACTFUL RESEARCH ON INFORMATION SYSTEMS FOR ENVIRONMENTAL SUSTAINABILITY', MIS Q., vol. 37, no. 4, 2013.

[16] F. T. C. Tan, M. Cahalane, B. Tan, and J. Englert, 'How GoGet CarShare's ProductService System is Facilitating Collaborative Consumption', MIS Q. Exec., vol. 16, no. 4, pp. 265-277, 2017.

[17] R. T. Watson, M.-C. Boudreau, and A. J. Chen, 'Information Systems and Environmentally Sustainable Development: Energy Informatics and New Directions for the IS Community', Source MIS Q., vol. 34, no. 1, pp. 23-38, 2010.

[18] F. Lüdeke-Freund, 'Towards a Conceptual Framework of 'Business Models for Sustainability', in ,Knowledge Collaboration \& Learning for Sustainable Innovation “ - Conference Proceedings, 14th European Roundtable on Sustainable Consumption And Production (ERSCP) \& 6th Environmental Management for Sustainable Universities (EMSU), 2529 October 2010, 2010.

[19] W. Kathan, K. Matzler, and V. Veider, 'The sharing economy: Your business model's friend or foe?', Bus. Horiz., vol. 59, no. 6, pp. 663-672, Nov. 2016.

[20] P. Davidsson, B. Hajinasab, J. Holmgren, A.. Jevinger, and J. Persson, 'The Fourth Wave of Digitalization and Public Transport: Opportunities and Challenges', Sustainability, vol. 8, no. 12, p. 1248, Nov. 2016.

[21] M. Nasiri, N. Tura, and V. Ojanen, 'Developing Disruptive Innovations for Sustainability: A Review on Impact of Internet of Things (IOT)', in 2017 Proceedings of PICMET '17: Technology Management for Interconnected World, 2017.

[22] C. Jose, C. Jabbour, A. B. Lopes De Sousa Jabbour, J. Sarkis, and G. Filho, 'Unlocking the circular economy through new business models based on large-scale data: An integrative framework and research agenda', Technol. Forecast. Soc. Chang., 2017.

[23] S. Schaltegger, E. G. Hansen, and F. Lüdeke-Freund, 'Business Models for Sustainability: Origins, Present Research, and Future Avenues', Organ. Environ., vol. 29, no. 1, pp. 3-10, 2016.

[24] N. Bocken, S. W. Short, P. Rana, and S. Evans, 'A literature and practice review to 
develop sustainable business model archetypes', J. Clean. Prod., vol. 65, pp. 42-56, 2014.

[25] B. Hildebrandt, A. Hanelt, and S. Firk, 'Sharing Yet Caring: Mitigating Moral Hazard in Access-Based Consumption through IS-Enabled Value Co- Capturing with Consumers', Bus. Inf. Syst. Eng., vol. 60, no. 3, 2018.

[26] G. Lyons, 'Getting smart about urban mobility - Aligning the paradigms of smart and sustainable', Transp. Res. Part A, 2016.

[27] S. Ali, L. Hongqi, S. U. Khan, and Y. Zhongguo, 'Practices in Software Outsourcing Partnership: Systematic Literature Review Protocol with Analysis', J. Comput., vol. 13, no. 7, pp. 839-861, 2018.

[28] B. Kitchenham and S. Charters, 'Guidelines for performing Systematic Literature Reviews in Software Engineering', 2007.

[29] C. Okoli and K. Schabram, 'A Guide to Conducting a Systematic Literature Review of Information Systems Research', Sprouts Work. Pap. Inf. Syst., vol. 10, no. $26,2010$.

[30] A. Troman, N. Jacobs, and S. Copeland, 'A new electronic service for UK theses: access transformed by EThOS', Interlend. Doc. Supply, vol. 35, no. 3, pp. 157-163, 2007.

[31] L. Piscicelli, G. D. S. Ludden, and T. Cooper, 'What makes a sustainable business model successful? An empirical comparison of two peer-to-peer goods-sharing platforms', $J$. Clean. Prod., vol. 172, pp. 4580-4591, 2018.

[32] F. Molinari, 'Innovative Business Models for Smart Cities: Overview of Recent Trends', in Proceedings of the 12th European Conference on eGovernment, 2012.

[33] M. Heiskala, J.-P. Jokinen, and M. Tinnilä, 'Crowdsensing-based transportation services - An analysis from business model and sustainability viewpoints', Res. Transp. Bus. Manag., vol. 18, pp. 38-48, 2016.

[34] Y. Jaghbeer, S. I. Hallstedt, T. Larsson, and J. Wall, 'Exploration of simulation-driven support tools for sustainable product development', in Procedia CIRP, 2017, vol. 64, pp. 271-276.

[35] A. Merluzzi and G. Brunetti, 'Metals Industry: Road to Digitalization.', in 2017 40th International Convention on Information and Communication Technology, Electronics and Microelectronics, MIPRO 2017 - Proceedings, 2017.

[36] A. W. Ng, A. K. L. Wong, and T. M. Wut, 'Second-movers' advantage of utilizing Big Data to enhance sustainability performance: the case of elevator industry', in Proceedings of the International Conference on Industrial Engineering and Operations Management, 2016.

[37] J. Cornelis De Man and J. O. Strandhagen, 'An Industry 4.0 research agenda for sustainable business models', in Procedia CIRP, 2017, vol. 63, pp. 721-726.

[38] M. Moreno et al., 'Re-distributed manufacturing to achieve a Circular Economy: A case study utilizing IDEF0 modeling', in Procedia CIRP, 2017, vol. 63, pp. 686-691.

[39] J. Hedman, S. Henningsson, and L. Selander, 'ORGANIZATIONAL SELFRENEWAL: THE ROLE OF GREEN IS IN DEVELOPING ECO-EFFECTIVENESS', in ICIS 2012 PROCEEDINGS, 2012.

[40] J. M. V Cedeño, J. Papinniemi, L. Hannola, and I. Donoghue, 'Developing smart services by internet of things in manufacturing business', LogForum, vol. 14, no. 1, pp. 59-71, 2018. 